\title{
The impact of physiological peripartal stress on the lifelong health of newborn
}

\author{
Hederlingova $\mathbf{J}^{1}$, Psenkova $\mathrm{P}^{2}$, Zahumensky $\mathbf{J}^{2,3}$ \\ 1st Department of Gynaecology and Obstetrics, Faculty of Medicine, Comenius University \\ and University Hospital, Bratislava, Slovakia. jozef.zahumensky@fmed.uniba.sk
}

\begin{abstract}
In the last decades the exponential increase in frequency of Caesarean sections is being observed. At the same time, there is growing amount of epidemiologic data showing higher lifetime risk of incidence of several diseases in offspring who do not experience natural labour. These findings lead to investigation of mechanisms which are responsible for maladaptation of several organ systems. Authors of this article describe these mechanisms, focusing especially on epigenetic programming, production of microbiome and positive effect of peripartal stress on successful beginning of extrauterine life.

The best prevention strategy is following the strict indications of elective Caesarean sections. The current trend worldwide is to prepare the chronically ill patient for vaginal birth instead of indicating elective Caesarean section. From obstetric point of view it is possible to offer the external version of the foetus in breech presentation, the possibility of vaginal birth after Caesarean section and leave out controversial indications. The inevitable elective Caesarean sections should be planned close to term or after the beginning of spontaneous labour. The composition of intestinal microbiome could be partially influenced by application of vaginal secretion on newborn born by Caesarean section but there is not enough data proving long term positive outcomes (Ref. 48). Text in PDF www.elis.sk.

KEY WORDS: birth stress, labour, vaginal delivery, Caesarean section, immunity, microbiome.
\end{abstract}

\section{Introduction}

Caesarean section is probably the most common major surgery performed nowadays. According to the estimation of $10 \%$ infants being born by Caesarean section worldwide, it is possible to estimate that 13 million of these procedures are performed every year. That indicates the amount of 24 Caesarean deliveries performed every minute (1).

It is well known that the rate of Caesarean sections in developed countries is constantly rising. This trend is also observed in Czech Republic (12.5\% Caesarean delivery rate reached in 1998 went up to $25.6 \%$ in 2013 ) and Slovakia (13.43\% rate reached in 1998 , up to $31.0 \%$ in 2013) (source: www.uzis.cz, www.nczisk. sk). Czech Republic and Slovakia together with Hungary, Ireland and Austria have shown the highest incline of the Caesarean delivery rate among developed countries during 1992-2007. The rate increased more than twice during this period (2).

${ }^{1} 1$ st Department of Gynaecology and Obstetrics Faculty of Medicine, Comenius University and University Hospital, Bratislava, Slovakia, ${ }^{2} 2$ nd Department of Gynaecology and Obstetrics Faculty of Medicine, Comenius University and University Hospital, Bratislava, Slovakia, and ${ }^{3}$ Department of Obstetrics and Gynecology, Brno University Hospital and Masaryk University Medical Faculty, Brno, Czech Republic

Address for correspondence: J. Zahumensky, 2nd Department of Gynaecology and Obstetrics Faculty of Medicine, Comenius University and University Hospital, Ruzinovska 6, SK-821 06 Bratislava, Slovakia.

Phone: +421.918900860
As a result of exponential growth of Caesarean delivery rate, there is accumulation of epidemiologic data worldwide showing increased risk of severe lifetime complications in offspring born by Caesarean section. It is assumed that vaginal birth is associated with important physiological mechanisms in newborn which positively affect the occurrence of several disorders during the lifetime, mainly related to the immune system.

\section{Attempting to analyze the problem}

Three pathophysiologic mechanisms are thought to contribute to a greater risk of developing disorders in infants born by Caesarean section: the type of microbiome the newborn is exposed to depending on the mode of delivery, the absence of adaptive stress during the Caesarean delivery and alterion epigenetic regulation of gene expression. Another important factor is scheduled timing of elective Caesarean section. The calculation of due date may be incorrect and in addition, there is an individual gestational age and interindividual variability in maturing of organ systems in every foetus. According to published data, $9 \%$ of newborns is born immature because of incorrectly calculated due date (3).

\section{Microbiome}

Newborns delivered vaginally are colonized by bacteria species originating from the birth canal and perianal region of the mother, while newborns born by Caesarean section are colonised 
by bacteria species from the hospital environment (4). Early contact of the newborn with bacteria permanently modifies immunological development (5). Neonatal intestinal colonization by bacteria allows finishing of maturation of the newborn immune system and changes the balance between type 1 and type 2 helper T-cells. Different intestinal colonization of children born by Caesarean section prolongs postnatal immaturity of their immune system causing increased risk of occurrence of immune disorders in their later lives (6). It was demonstrated that infants born by Caesarean section have their intestined colonized by higher numbers of clostridia and lower numbers of bifidobacteria and bacteroides. These abnormal changes in bacterial intestinal microflora remain until 7 years of age (7). Recent study has shown high levels of intestinal colonization by bacteria originating from the hospital environment such as Citrobacter, Clostridium, Enterobacter and Klebsiella (8). This kind of intestinal microflora can persist until the adult age (9).

\section{The peripartal stress}

Contraction of the uterus causes decreased blood flow in uterine arteries which leads to limited gas exchange between foetus and mother. The temporary physiologic hypoxia of the foetus stimulates a stress response characterized by high catecholamine and corticoids levels in newborns. Levels of these stress hormones are significantly lower in neonates born by Caesarean section (10). Higher levels of corticoids play an important role in maturing of various organ systems, mainly lungs and intestines. They are also used therapeutically in pharmacologic induction of fetal lung maturity during the preterm delivery. Lower levels of thyroid hormones in umbilical cord blood in infants born by Caesarean section are probably the cause of impaired thermoregulation. Infants born by Caesarean section suffer more often from hypothermia in first 90 minutes after the birth (11). Poor activation of hypothalamicpituitary-adrenal axis along with unfinished intrauterine fetal development caused by earlier due date plays an important role in developing chronic illnesses in later life.

\section{Prenatal programming}

Important factor of epigenetic programming is the interference of environmental factors into transmission of biological signals from genetic material by affecting the gene transcription and thus allowing the modification of the phenotype. During the period of prenatal life and first years after the birth there is high sensitivity to epigenetic alterations and histone modifications through DNA methylation (12). Corticoids are strong DNA methylators which shut down the fetal genes during delivery. Methylation of DNA loci of CD 34 lymphocytes shows different levels in infants born by Caesarean section and those delivered vaginally. This process affects directly production of antibodies, glycolysis regulation and regulation of response to food allergens (13). The perinatal programming is probably the reason for higher risk of metabolic disorders such as obesity and diabetes mellitus in infants born by Caesarean section.

\section{Caesarean section and development of immune system}

Physiological stress during the labour influences the composition and function of immune cells in blood plasma. Infants born by elective Caesarean section have lower levels of leukocytes in peripheral blood $(14,15)$. It mainly applies to neutrophils, monocytes and NK cells. In addition, leukocytes harvested from umbilical cord blood of infants born by Caesarean section show decreased migration activity and lower expression of adhesion molecules on their membranes such as CD11b and CD18 $(16,17)$. The overall activity of leukocytes is decreased as well, such as the ability to release the proinflammatory cytokines, for example IL4r, IL1beta, IL-6 and TNF alfa (18). Infants born by Caesarean section produce increased levels of IgA and IgG in one year of age in comparison to infants delivered vaginally. The increased antibodies response is also characteristic for those affected by atopic reaction (19).

\section{Autoimmune disorders}

The large Danish study performed in 750000 infants unveiled higher risk of developing asthma, allergic laryngitis, gastroenteritis, ulcerative colitis, celiac disease and juvenile idiopathic arthritis in infants born by Caesarean section (20). The metaanalysis of 23 studies has shown that infants born by elective Caesarean section have $20 \%$ higher risk of developing bronchial asthma later in their lives (21). This relation stays unchanged even after exclusion of other factors such as smoking of the mother, low birthweight and duration of breastfeeding. Higher risk is proven to exist for early onset of bronchial asthma, which shows up before fifth year of age (22). Elective Caesarean section often leads to early neonatal respiratory morbidity. This represents the first insult of the lung tissue, which is then more susceptible to pathological condition in later life (23). Furthermore, in children born by Caesarean section the higher risk of atopy and allergic rhinitis has been observed (24). A few studies discovered a connection between food allergy and Caesarean delivery, especially in children with atopic parents $(25,26)$. The risk of avascular necrosis of the femoral head is $36 \%$ higher in children born by Caesarean delivery than in those born vaginally, even after exclusion of breech delivery (27).

\section{Oncologic disorders}

Infants born by Caesarean section are in greater risk of several cancer diseases. The exact reasons remain unknown, the maladaptation of immune system is being considered. Older study demonstrated 2.5 times higher risk of childhood myeloid leukemia in offspring born by Caesarean section with exclusion of those with Down syndrome (28). Elective Caesarean section increases the risk of developing childhood acute myeloid leukemia by $79 \%$, the risk increase is related mostly to the precursor B-ALL (29). Recent analysis of registers from 9 different countries proved 23 $\%$ higher risk of developing acute lymphocytic leukemia in infants born by Caesarean section. The connection between the mode of delivery and acute myeloid leukemia was not proven (30). Elective Caesaren section appears to be one of the risk factors for neuro- 
blastoma. In infants older than is 18 months the risk elevated to $40 \%$ (31) recent study demonstrated that the risk is even $72 \%$ higher (32). Caesarean delivery increases the risk of nonseminoma testicular cancer more than twice (33). Metaanalysis of 3 studies from USA found out there is $67 \%$ higher risk of discovering this type of cancer in boys born by Caesarean section (34).

\section{Metabolic disorders}

The abnormal intestinal microflora in offspring born by Caesarean section might be the reason of higher prevalence of certain metabolic abnormalities. Children born by Caesarean section have in their 11 years of age 1.83 times higher prevalence of overweight and obesity (35). Metaanalysis of 28 studies has shown that the risk of obesity in offspring born by Caesarean section is by $39 \%$ higher with no connection to overweight of mother or other perinatal factors (36). Likewise, metaanalysis of 12 studies demonstrated that the risk of developing diabetes mellitus type I in children born by Caesarean sections is by $19 \%$ higher even after clearing other factors (age of mother, breastfeeding, birthweight, gestational age, history of the mother) (37).

\section{Mental disorders and psychiatric conditions}

Infants born by Caesarean section have 2.5 times higher risk of developing bipolar disorder in their later lives (38). Also, those born by elective Caesarean section have $13 \%$ higher risk of developing and revealing affective and non-affective psychosis including schizophrenia in adulthood (39). Metaanalysis of 13 studies has shown $23 \%$ higher risk of developing autistic spectrum disorders in offspring born by Caesarean section (40). Other study demonstrated higher risk of developing autistic spectrum disorders only when general anaesthesia is being administered during the surgical procedure (41). At the age of three months children born by Caesarean section show slower reactivity to external stimuli while their cognitive functions and attention stay untouched (42).

The connection between the composition of intestinal microbiome and behaviour disorders, mainly autistic spectrum disorders, is well known. An experimental study on mice proved that subjects born by Caesarean section have different composition of intestinal microbiome and show markedly higher levels of anxious behaviour and signs of depression (43). In children with autism a lower count of fermenting bacteria in the intestinal tract was detected (44). The influence of impaired immune mechanisms, neuronal signals transmitted via nervus vagus and the production of neurotransmitters (GABA) by bacteria is being considered to affect directly the functions of the brain (45). Lower levels of uncoupling proteins type 2 (UCP-2) were found in umbilical cord blood of offsprings born by Caesarean section. These proteins are found on superficial membranes of mitochondria and it is anticipated that they are protecting the brain neurons from damage caused by oxidative stress (46).

\section{The main prevention strategy}

The best prevention strategy is following the strict indications of elective Caesarean sections. The current trend worldwide is to prepare the chronically ill patient for vaginal birth instead of indicating elective Caesarean section. For example, bronchial asthma is not an indication for elective Caesarean section anymore. On the contrary, atopic mother significantly increases the risk of disease in the infant. Also, there is not an ophthalmological indication for Caesarean section anymore.

The inevitable elective Caesarean sections should be planned as close to the calculated due date as possible, preferably after completed 39th week of pregnancy. Administration of corticoids to the mother before elective Caesarean section in term decreases the risk of early respiratory morbidity of the foetus and the need of mechanical ventilation in neonate (47). This approach is not yet approved as routine by accredited by gynecological and obstetrical societies. The composition of intestinal microbiome could be partially influenced by application of vaginal secretion on newborn born by Caesarean section but there is not enough data proving long term positive outcomes (48).

\section{References}

1. Brocklehurst P, Quigley M, Ayers S, Juszczak E, Anderson E, Bowler U. Caesarean section surgical techniques: a randomised factorial trial (CAESAR). BJOG 2010; 117 (11): 1366-1376.

2. Declercq E, Young R, Cabral H, Ecker J. Is a rising cesarean delivery rate inevitable? Trends in industrialized countries, 1987 to 2007. Birth 2011; 38 (2): 99-104.

3. Sinha A, Bewley S, McIntosh T. Myth: babies would choose prelabour caesarean section. Semin Fetal Neonatal Med 2011; 16 (5): 247-253.

4. Dominguez-Bello MG, Costello EK, Contreras M et al. Delivery mode shapes the acquisition and structure of the initial microbiota across multiple body habitats in newborns. Proc Natl Acad Sci USA 2010; 107 (26): 11971-11975.

5. Neu J, Rushing J. Cesarean Versus Vaginal Delivery: Long-term Infant Outcomes and the Hygiene Hypothesis. Clin Perinatol 2011; 38 (2): 321-331.

6. Ly NP, Ruiz-Pérez B, Onderdonk AB et al. Mode of delivery and cord blood cytokines: a birth cohort study. Clin Mol Allergy 2006; 4: 13.

7. Salminen S, Gibson GR, McCartney AL, Isolauri E. Influence of mode of delivery on gut microbiota composition in seven year old children. Gut 2004; 53 (9): 1388-1389. doi: 10.1136/gut.2004.041640.

8. Stokholm J, Thorsen J, Chawes BL et al. Cesarean section changes neonatal gut colonization. J Allergy Clin Immunol April 2016.

9. Goedert JJ, Hua X, Yu G, Shi J. Diversity and composition of the adult fecal microbiome associated with history of cesarean birth or appendectomy: Analysis of the American Gut Project. EBioMedicine 2014; 1 (2-3): 167-172.

10. Lagercrantz H, Slotkin TA. The "stress" of being born. Sci Am 1986; 254 (4): 100-107.

11. Christensson K, Siles C, Cabrera T et al. Lower body temperatures in infants delivered by caesarean section than in vaginally delivered infants. Acta Paediatr 1993; 82 (2): 128-131.

12. Desplats P. Perinatal programming of neurodevelopment: epigenetic mechanisms and the prenatal shaping of the brain. Adv Neurobiol 2015; 10: 335-361. 
13. Almgren M, Schlinzig T, Gomez-Cabrero D et al. Cesarean delivery and hematopoietic stem cell epigenetics in the newborn infant: implications for future health? Am J Obstet Gynecol 2014; 211 (5): 502.e1-8.

14. Nikischin W, Peter M, Oldigs HD. The influence of mode of delivery on hematologic values in the umbilical vein. Gynecol Obstet Invest 1997; 43 (2): 104-107.

15. Sparrow RL, Cauchi JA, Ramadi LT, Waugh CM, Kirkland MA. Influence of mode of birth and collection on WBC yields of umbilical cord blood units. Transfusion 2002; 42 (2): 210-215.

16. Gessler $P$, Dahinden $C$. Increased respiratory burst and increased expression of complement receptor-3 (CD11b/CD18). and of IL-8 receptorA in neutrophil granulocytes from newborns after vaginal delivery. Biol Neonate 2003; 83 (2): 107-112.

17. Yektaei-Karin E, Moshfegh A, Lundahl J, Berggren V, Hansson L-O, Marchini G. The stress of birth enhances in vitro spontaneous and IL-8-induced neutrophil chemotaxis in the human newborn. Pediatr Allergy Immunol 2007; 18 (8): 643-651.

18. Zanardo V, Soldà G, Trevisanuto D. Elective cesarean section and fetal immune-endocrine response. Int J Gynaecol Obstet 2006; 95 (1): 52-53.

19. Huurre A, Kalliomäki M, Rautava S, Rinne M, Salminen S, Isolauri E. Mode of delivery - effects on gut microbiota and humoral immunity. Neonatology 2008; 93 (4): 236-240.

20. Kristensen K, Henriksen L. Cesarean section and disease associated with immune function. J Allergy Clin Immunol. September 2015.

21. Thavagnanam S, Fleming J, Bromley A, Shields MD, Cardwell CR. A meta-analysis of the association between Caesarean section and childhood asthma. Clin Exp Allergy 2008; 38 (4): 629-633.

22. Metsälä J, Kilkkinen A, Kaila $M$ et al. Perinatal factors and the risk of asthma in childhood--a population-based register study in Finland. Am J Epidemiol 2008; 168 (2): 170-178.

23. Hyde MJ, Mostyn A, Modi N, Kemp PR. The health implications of birth by Caesarean section. Biol Rev Camb Philos Soc 2012; 87 (1): 229-243.

24. Renz-Polster H, David MR, Buist AS et al. Caesarean section delivery and the risk of allergic disorders in childhood. Clin Exp Allergy 2005; 35 (11): 1466-1472.

25. Laubereau B, Filipiak-Pittroff B, von Berg A et al. Caesarean section and gastrointestinal symptoms, atopic dermatitis, and sensitisation during the first year of life. Arch Dis Child 2004; 89 (11): 993-997.

26. Eggesbø M, Botten G, Stigum H, Nafstad P, Magnus P. Is delivery by cesarean section a risk factor for food allergy? J Allergy Clin Immunol 2003; 112 (2): 420-426.

27. Bahmanyar S, Montgomery SM, Weiss RJ, Ekbom A. Maternal smoking during pregnancy, other prenatal and perinatal factors, and the risk of Legg-Calvé-Perthes disease. Pediatrics 2008; 122 (2): 459-64.

28. Cnattingius S, Zack M, Ekbom A, Gunnarskog J, Linet M, Adami HO. Prenatal and neonatal risk factors for childhood myeloid leukemia. Cancer Epidemiol Biomarkers Prev 4 (5): 441-445.

29. Thomopoulos TP, Skalkidou A, Dessypris N et al. Prelabor cesarean delivery and early-onset acute childhood leukemia risk. Eur J Cancer Prev. March 2015.

30. Marcotte EL, Thomopoulos TP, Infante-Rivard $\mathrm{C}$ et al. Caesarean delivery and risk of childhood leukaemia: a pooled analysis from the Childhood Leukemia International Consortium (CLIC). Lancet Haematol 2016; 3 (4): e176-85.
31. McLaughlin CC, Baptiste MS, Schymura MJ, Zdeb MS, Nasca PC. Perinatal risk factors for neuroblastoma. Cancer Causes Control 2009; 20 (3): 289-301.

32. Urayama KY, Von Behren J, Reynolds P. Birth characteristics and risk of neuroblastoma in young children. Am J Epidemiol 2007; 165 (5): 486-495.

33. Cook MB, Graubard BI, Rubertone M V, Erickson RL, McGlynn KA. Perinatal factors and the risk of testicular germ cell tumors. Int J Cancer 2008; 122 (11): 2600-2606.

34. Cook MB, Akre O, Forman D, Madigan MP, Richiardi L, McGlynn KA. A systematic review and meta-analysis of perinatal variables in relation to the risk of testicular cancer--experiences of the mother. Int $\mathrm{J}$ Epidemiol 2009; 38 (6): 1532-1542.

35. Blustein J, Attina T, Liu M et al. Association of caesarean delivery with child adiposity from age 6 weeks to 15 years. Int J Obes (Lond) 2013; 37 (7): 900-906.

36. Kuhle S, Tong OS, Woolcott CG. Association between caesarean section and childhood obesity: a systematic review and meta-analysis. Obes Rev 2015; 16 (4): 295-303.

37. Cardwell CR, Stene LC, Joner G et al. Caesarean section is associated with an increased risk of childhood-onset type 1 diabetes mellitus: a meta-analysis of observational studies. Diabetologia 2008; 51 (5): 726-735.

38. Chudal R, Sourander A, Polo-Kantola $P$ et al. Perinatal factors and the risk of bipolar disorder in Finland. J Affect Disord 2014; 155: 75-80.

39. O'Neill SM, Curran EA, Dalman C et al. Birth by Caesarean Section and the Risk of Adult Psychosis: A Population-Based Cohort Study. Schizophr Bull 2016; 42 (3): 633-641.

40. Curran EA, O’Neill SM, Cryan JF et al. Research review: Birth by caesarean section and development of autism spectrum disorder and attention-deficit/hyperactivity disorder: a systematic review and meta-analysis. J Child Psychol Psychiatry 2015; 56 (5): 500-508.

41. Chien L-N, Lin H-C, Shao Y-HJ, Chiou S-T, Chiou H-Y. Risk of autism associated with general anesthesia during cesarean delivery: a populationbased birth-cohort analysis. J Autism Dev Disord 2015; 45 (4): 932-942.

42. Adler SA, Wong-Kee-You AMB. Differential attentional responding in caesarean versus vaginally delivered infants. Atten Percept Psychophys 2015; 77 (8): 2529-2539.

43. Reardon S. Gut-brain link grabs neuroscientists. Nature 2014; 515 (7526): 175-177.

44. Kang D-W, Park JG, Ilhan ZE et al. Reduced incidence of Prevotella and other fermenters in intestinal microflora of autistic children. PLoS One 2013; 8 (7): e68322.

45. Barrett E, Ross RP, O'Toole PW, Fitzgerald GF, Stanton C. $\gamma$-Aminobutyric acid production by culturable bacteria from the human intestine. J Appl Microbiol.

46. Aslan Y, Kader Ş, Mutlu M et al. The effect of delivery type on uncoupling protein-2 levels. J Matern Fetal Neonatal Med. November 2015: 1-4.

47. Sotiriadis A, Makrydimas G, Papatheodorou S, Ioannidis JP. Corticosteroids for preventing neonatal respiratory morbidity after elective caesarean section at term. Cochrane database Syst Rev 2009; (4): CD006614.

48. Dominguez-Bello MG, De Jesus-Laboy KM, Shen N et al. Partial restoration of the microbiota of cesarean-born infants via vaginal microbial transfer. Nat Med 2016; 22 (3): 250-253.

Received February 21, 2017. Accepted March 1, 2017. 